\title{
Experimental Investigation of Temperature on Interfacial Tension and its Relation to Alterations of Hydrocarbon Properties in a Carbonated Water/ Hydrocarbon System
}

\author{
Aly A. Hamouda and Nikhil Bagalkot
}

\begin{abstract}
The study addresses interfacial tension (IFT), and mass transfer in carbonated water (CW)/hydrocarbon systems, using the axisymmetric drop shape analysis (ADSA). Experiments and a mathematical model was used for $\mathrm{CW}+n$-decane system of non-isobaric (10-70 bar) and non-isothermal conditions $\left(25^{\circ} \mathrm{C}, 35^{\circ} \mathrm{C}\right.$, and $\left.45^{\circ} \mathrm{C}\right)$ using the axisymmetric drop shape analysis (ADSA). Further, the study addresses the inconsistencies of the reported in results reported in the literature between temperature and IFT.

The experimental results (volume changes) and analytical equations have been used to develop a compositional model to estimate the mass of $\mathrm{CO}_{2}$ diffused into hydrocarbon and the density of n-decane+ $\mathrm{CO}_{2}$ as a function of time, pressure, and temperature. The obtained densities are then used to estimate real-time and the equilibrium IFT from the pendant drop experiments. The results indicated that for $\mathrm{CW}$-n-decane system equilibrium IFT increases as pressure increases $(10-60$ bar), depicting an opposite trend to that observed for the $\mathrm{CO}_{2}$-n-decane system. This was shown to be related to the density difference between the hydrocarbon and the carbonated water, and $\mathrm{CO}_{2}$ solubility. Further, it was observed that the IFT was inversely related to temperature, which was credited to the changes in the kinetic energy and entropy. Among the three chosen temperatures, it was observed that the IFT at $35^{\circ} \mathrm{C}$ did not display the same behaviour as that at $25^{\circ} \mathrm{C}$ and $45^{\circ} \mathrm{C}$ with pressure and temperature. Up to a certain pressure the IFT at $35^{\circ} \mathrm{C}$ was lower than at $45^{\circ} \mathrm{C}$, and beyond this pressure, the IFT at $35^{\circ} \mathrm{C}$ was greater than at $45^{\circ} \mathrm{C}$.

The present article takes a step in resolving the controversy of IFT vs temperature and building the knowledge by carrying out a non-isothermal and non-isobaric study on the influence of temperature on the IFT in a system containing carbonated water and hydrocarbon. Further, the study gives an insight into the feasibility of carbonated water injection as a successful recovery process.
\end{abstract}

Index Terms - Carbonated water injection, interfacial tension, pressure, temperature.

\section{INTRODUCTION}

Carbonated water injection (CWI) is gradually gaining significance as an effective enhanced oil recovery (EOR) method and a solution for long-term or permanent sequestration of $\mathrm{CO}_{2}$. The increased interest is due to the fact that CWI overcomes the problems associated with the widely applied $\mathrm{CO}_{2}$ EOR. The mobility of the carbonated water in

Manuscript received February 17, 2018; revised March 30, 2018.

The authors are with Department of Petroleum Engineering, University of Stavanger, Norway $4036 \quad$ (email: aly.hamouda@uis.no, nikhil.bagalkot@uis.no). contrast with oil is more favorable than $\mathrm{CO}_{2}$ in the gas-oil system as it forms a single phase, this helps in overcoming the poor sweep efficiency and early breakthrough associated with $\mathrm{CO}_{2}$ injection [1], [2]. Carbonated water injection is particularly beneficial in watered-out reservoirs in which high water saturation adversely affects the $\mathrm{CO}_{2}$ injection performance [3]. In the majority of the cases, $\mathrm{CO}_{2}$ is not available readily, and the actual cost of capture, compression and transport to the reservoir it incurs is high. Therefore, making $\mathrm{CO}_{2}$-EOR infeasible especially in the fields that are far away from the source. The Carbonated Water Injection forms an alternative $\mathrm{CO}_{2}$ injection strategy that uses a smaller amount of $\mathrm{CO}_{2}$ (available from nearby oil and gas fields) and yet can lead to an increase in oil recovery.

Whether it is $\mathrm{CO}_{2}$-EOR or CWI the swelling and the resulting hydrocarbon mobility are the primary physics governing the oil recovery. The degree of swelling and the mobility depends on the mass transfer of the $\mathrm{CO}_{2}$ into the displaced fluid (hydrocarbon) from the displacing fluid $\left(\mathrm{CO}_{2}\right.$ or $\mathrm{CW}$ ). The interfacial tension between the displacing fluid and displaced fluid is a major parameter that controls the mass transfer and hence, the extent of oil recovery. Therefore, it is critical to study and understand the interfacial tension between CW and hydrocarbon and further identify the parameters influencing the IFT for optimising CWI.

Although, many studies have been carried out on IFT of $\mathrm{CO}_{2}$-hydrocarbon system few studies have focused on $\mathrm{CW}$-hydrocarbon system. Further, most of the studies on $\mathrm{CO}_{2}$ and CW-hydrocarbon system, have overlooked the influence of temperature on the IFT due to its unpredictable relation. At present, there is a lot of discrepancies associated with IFT vs temperature relationship, Mackay and Hossain [4] has reported an inverse relation of IFT with temperature, while Yang, et al. [5] has reported a direct relation. Hence, it is important to try to remove or understand why there is a discrepancy when it comes to the influence of temperature on IFT of CW-hydrocarbon system. Apart from the calculation of IFT, it is important to identify the parameters that are influencing and are influenced by the IFT, to optimise the process by possible alteration of these parameters.

The present study through experiments and mathematical model addresses the influence of temperature on the interfacial tension (IFT) for a system consisting of carbonated water (CW)-n-decane at non-isothermal and non-isobaric conditions. Further, the study addresses the inconsistencies in results reported in the literature between temperature and IFT. 
The experiment was designed to resemble the contact between CW and residual oil, as CW is injected, and to successfully use the results in flooding experiments. An Axisymmetric Drop Shape Analysis (ADSA) pendant drop technique has been used to carry out IFT analysis for a pressure range of $10-70$ bar and at $25^{\circ} \mathrm{C}, 35^{\circ} \mathrm{C}$, and $45^{\circ} \mathrm{C}$. IFT during the diffusion (dynamic) and at the end of diffusion (equilibrium IFT) has been estimated. The experimental result (volume variations) has been used in the mathematical model to estimate the mass of $\mathrm{CO}_{2}$ diffused into hydrocarbon from $\mathrm{CW}$, and hydrocarbon density at different time intervals. The obtained densities of CW and hydrocarbon are then used to extract real-time IFT from the experimental data.

\section{PROCEDURE}

\section{A. Materials}

The $n$-decane was used as the hydrocarbon sample for the drop phase, manufactured by Merck KGaA (purity 99\%). $\mathrm{CO}_{2}$ with the purity of $99.9 \%$ (PRAXAIR) was used to prepare the CW. NIST Chemistry Web Book [6] is the source of density and viscosity measurements at various pressures and temperatures of $n$-decane and $\mathrm{CO}_{2}$. The $\mathrm{CO}_{2}$ solubility, and hence, the density of $100 \%$ saturated CW was calculated using model presented by [7].

\section{B. Experimental Setup and Procedure}

A high-pressure pendant drop apparatus (PD-E1700 LL-H) manufactured by EUROTHECHNICA and KRUSS was utilised to carry out axisymmetric pendant drop experiments. Schematics of the experimental setup along with its essential components used in the present work is presented in Fig. 1. The important part of the setup is the corrosion resistant cylindrical high-pressure chamber (VC) (diameter of $18 \mathrm{~mm}$ ), with a maximum working pressure and temperature of 68.9 $\mathrm{MPa}$ and $180^{\circ} \mathrm{C}$ respectively. A thermocouple (NiCr-Ni) controls the temperature inside the VC. A pump (maximum pressure of $32 \mathrm{MPa}$, GILSON) connected to $\mathrm{CO}_{2}$ cylinder maintains the required pressure inside the $\mathrm{VC}$. The $\mathrm{VC}$ has a see-through window and is placed between a high-resolution camera (CF03) and a light source. The camera acquires digital images of the PD (hydrocarbon pendant drop), as the $\mathrm{CO}_{2}$ from the surrounding CW, diffuses into PD. A KRUSS DSA 100 software is used to analyse the captured images and compute the IFT at pre-set time intervals. The experimental method used in the present study to measure the IFT of the pendant drop is an automated process and devoid of any human interference.

At the beginning of the experiment, the high-pressure chamber (VC) is filled partially with deionised water (DIW) (20 $\mathrm{ml}$ of $25 \mathrm{ml}$ capacity), this is followed by the injection of $\mathrm{CO}_{2}$ at experimental pressure. The $\mathrm{CO}_{2}$ is injected into DIW present in the $\mathrm{VC}$ by the pump until the water reaches the saturation level of $\mathrm{CO}_{2}$ (at $\mathrm{P}$ and $\mathrm{T}$ ) and can no more accept $\mathrm{CO}_{2}$ into it. Further, experiments using flow meter confirmed that the between 95-98\% saturation was obtained in the VC when compared with results from the model presented by
Duan and Sun [8], hence, it is safe to assume that water is saturated with $\mathrm{CO}_{2}$ (saturated $\mathrm{CW}$ ). When it is made certain that the water is saturated with $\mathrm{CO}_{2}$, a hydrocarbon pendant drop (PD) is generated in the VC. The experimental setup was designed in a way that it replicates the physics occurring during the CWI (secondary). The detailed experimental procedure may be found in Bagalkot and Hamouda [9].

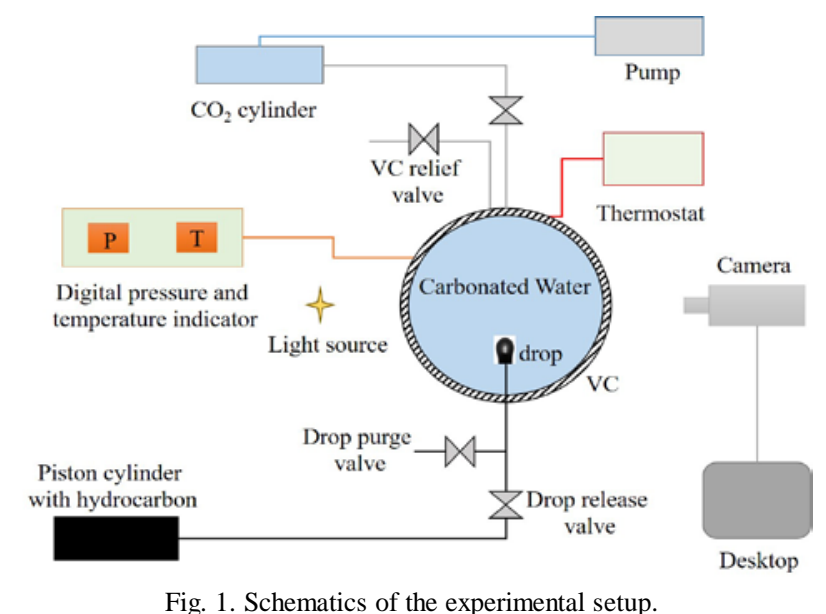

\section{Mathematical Model}

Alterations to the properties of hydrocarbon like density, viscosity, and volume are some of the critical phenomena occurring due the mass transfer of the $\mathrm{CO}_{2}$ into the hydrocarbon from the displacing fluid (CW). Among these properties the density changes are closely related to the IFT. Studying the changes in the density of the hydrocarbon due to mass transfer of $\mathrm{CO}_{2}$ would help us to understand the IFT better and gives us a depiction of the impact of the $\mathrm{CW}$ as a displacing fluid. To do obtain the density, the mass of $\mathrm{CO}_{2}$ transferred into the hydrocarbon as a function of time and at equilibrium need to be calculated. A relatively simple mathematical method that utilizes the experimental PD volume as input has been developed to calculate the mass of $\mathrm{CO}_{2}$ transferred into the PD (n-decane).

When the experiment is initiated (just before the diffusion of $\mathrm{CO}_{2}$ into the PD, time $t=0 \mathrm{~s}$ ) the PD consists only of hydrocarbon ( $100 \% n$-decane). As the diffusion of $\mathrm{CO}_{2}$ starts $(t>0)$, the mass transfer of $\mathrm{CO}_{2}$ into the pendant drop transpires, causing an increase in the volume of the $\mathrm{PD}$ and the additional volume is due to the mass of $\mathrm{CO}_{2}$ that has been diffused into the PD. Hence, the volume of the PD is the summation of the volume of n-decane and the increase in volume caused by the $\mathrm{CO}_{2}$ in the PD.

$$
V_{P D}(t)=V_{H C}+V_{C O 2}(t)
$$

where $V_{P D}(\mathrm{ml})$ is the volume of the pendant drop; $V_{H C}$ is the volume of the n-decane or the initial pendant drop volume, and $V_{\mathrm{CO} 2}(\mathrm{ml})$ is the volume of the $\mathrm{CO}_{2}$ in the pendant drop. The $V_{H C}$ is fixed and is not a function of time. Hence, the volume of $\mathrm{CO}_{2}\left(V_{\mathrm{CO} 2}\right)$ is the volume of $n$-decane subtracted from that of total volume at a given instant.

$$
V_{C O 2}(t)=V_{P D}(t)-V_{H C}
$$


In the equation 2, $t$ is the time. The computed volume of $\mathrm{CO}_{2}(\mathrm{ml})$ is then multiplied by the $\mathrm{CO}_{2}$ density $(\mathrm{g} / \mathrm{ml})$ at the experimental pressure and temperature to calculate the mass of $\mathrm{CO}_{2}$ (equation 3).

$$
M_{\mathrm{CO} 2}(t)=\left(\rho_{\mathrm{CO} 2} * V_{\mathrm{CO} 2}(t)\right)_{P, T}
$$

In the equation 3 the $\rho_{\mathrm{CO} 2}$ is the density of $\mathrm{CO}_{2}$ and is obtained from NIST web book [6] and $M_{\mathrm{CO} 2}$ is the mass of $\mathrm{CO}_{2}$ in grams. From the computed $\mathrm{CO}_{2}$ mass, the number of moles, mass fraction, and mole fraction of $\mathrm{CO}_{2}$ and n-decane in the $\mathrm{PD}$ is calculated. Using, the determined mass and mole data of $\mathrm{CO}_{2}$ and n-decane the density of pendant drop (PD) may be calculated from the equation 4.

$$
\rho_{P D}(t)=\left(\left(V_{\mathrm{CO}_{2}}(t) \cdot \rho_{\mathrm{CO}_{2}}+\left(V_{\mathrm{HC}}(t) \cdot \rho_{\mathrm{HC}}\right)\right)_{P, T},\right.
$$

where $V_{\mathrm{CO} 2}$ and $V_{\mathrm{HC}}$ are the volume fractions of $\mathrm{CO}_{2}$ and n-decane in the drop respectively at required pressure and temperature, and $\rho_{\mathrm{CO} 2}$ and $\rho_{\mathrm{HC}}$ are the densities of $\mathrm{CO}_{2}$ and hydrocarbon respectively at $\mathrm{P}$ and $\mathrm{T}$.

\section{IFT Measurement and Data Gathering Procedure}

IFT measurements were carried out using the ADSA system. Diffusion of $\mathrm{CO}_{2}$ into the $\mathrm{PD}$, change the density of the $\mathrm{PD}$, which is directly proportional to the mass of $\mathrm{CO}_{2}$ transferred into the hydrocarbon (volume or mole fraction) (equation 3). So, for accurate dynamic measurement of the IFT, the density of the drop with $\mathrm{CO}_{2}$, is updated in the DSA 100 software to account for the density change. In the present study, the changes of the mole fraction of $\mathrm{CO}_{2}$ in the drop (from the start to the equilibrium) were calculated (equation 2). The dynamic density of $\mathrm{CO}_{2}$ (equation 4) was accordingly used to obtain the dynamic IFT of the CW-hydrocarbon system.

\section{RESUlts AND DiscUSSION}

The influence of pressure on dynamic IFT (IFT as a function of time or function of rate of $\mathrm{CO}_{2}$ mass transfer), and equilibrium IFT (at the end of mass transfer/diffusion), are presented in Fig. 2. The Fig. 2 shows the variation of IFT with time (0-300 min) for CW-n-decane system at $25^{\circ} \mathrm{C}, 35^{\circ} \mathrm{C}$, and $45^{\circ} \mathrm{C}$ for a pressure range of $10-60$ bar. A unique observation of Fig. 2 is the behaviour of IFT with time at various pressures and temperatures. At $25^{\circ} \mathrm{C}$ for low pressures (10 and 20 bar), the IFT of the system decreases with time and reaches an equilibrium value lower than the initial value, which is similar to the behaviour of the $\mathrm{CO}_{2}$-hydrocarbon system. However, above 20 bar there is a transition of the profile of IFT vs time, the IFT increases with time and reaches an equilibrium value greater than the initial. Hence, there exists a "threshold pressure", above which the IFT increases with time, and below which the IFT decreases. The same is true for other temperature $\left(35^{\circ} \mathrm{C}\right.$, and $\left.45^{\circ} \mathrm{C}\right)$, except that the transition occurs at different pressures, such that the threshold pressure increases as temperature increases, it is above 40 bar, and 50 bar for $35^{\circ} \mathrm{C}$ and $45^{\circ} \mathrm{C}$, respectively. Hence, there are two phenomena to be addressed. First is the occurrence of the threshold pressure, and the second is the increase of the threshold pressure with temperature. These phenomena are interrelated and may be explained based on the phase behaviour of the diffused fluid $\left(\mathrm{CO}_{2}\right)$ into $\mathrm{PD}$ (n-decane). The increment in the IFT with time at higher pressures (30-60 bar) at $25^{\circ} \mathrm{C}$ may be explained by the effect of $\mathrm{CO}_{2}$ diffusion on the density of the hydrocarbon. The diffusion of gaseous $\mathrm{CO}_{2}$ into the hydrocarbon reduces the density of the binary mixture $\left(\mathrm{CO}_{2}+n\right.$-decane), whereas the dissolution of $\mathrm{CO}_{2}$ into water increases the density of the mixture, this increases the density difference across the interface. Further, the magnitude of IFT is directly proportional to density difference [10], [11], hence, the greater the density difference, the larger will be the IFT. The reduction in the IFT with time at low pressures may be explained by the lack of $\mathrm{CO}_{2}$ mass transfer into the hydrocarbon from the $\mathrm{CW}$ at low pressures, due to low $\mathrm{CO}_{2}$ solubility in hydrocarbon and water at low pressures. Lower solubility of $\mathrm{CO}_{2}$ limits the diffusion of $\mathrm{CO}_{2}$ into the hydrocarbon and hence restricts the reduction in the density of the binary mixture. It may be observed from Table I that at $25^{\circ} \mathrm{C}$ and 10 bar there is approximately not more than $2.5 \%$ reduction in the density of n-decane. Therefore, at low pressure, there is a decrease in IFT. However, as pressure increases the $\mathrm{CO}_{2}$ solubility increases, leading to enhanced mass transfer and higher reduction in the density (28.4\% at 40 bar and $45.5 \%$ at 60 bar from Table I) of the n-decane and hence, the observed increase in IFT with time. So far, this may provide an explanation of the occurrence of the threshold pressure, but does not explain the upward shift of the threshold pressure with temperature $\left(20 \mathrm{bar}\right.$ at $35^{\circ} \mathrm{C}$ to 50 bar at $\left.45^{\circ} \mathrm{C}\right)$.

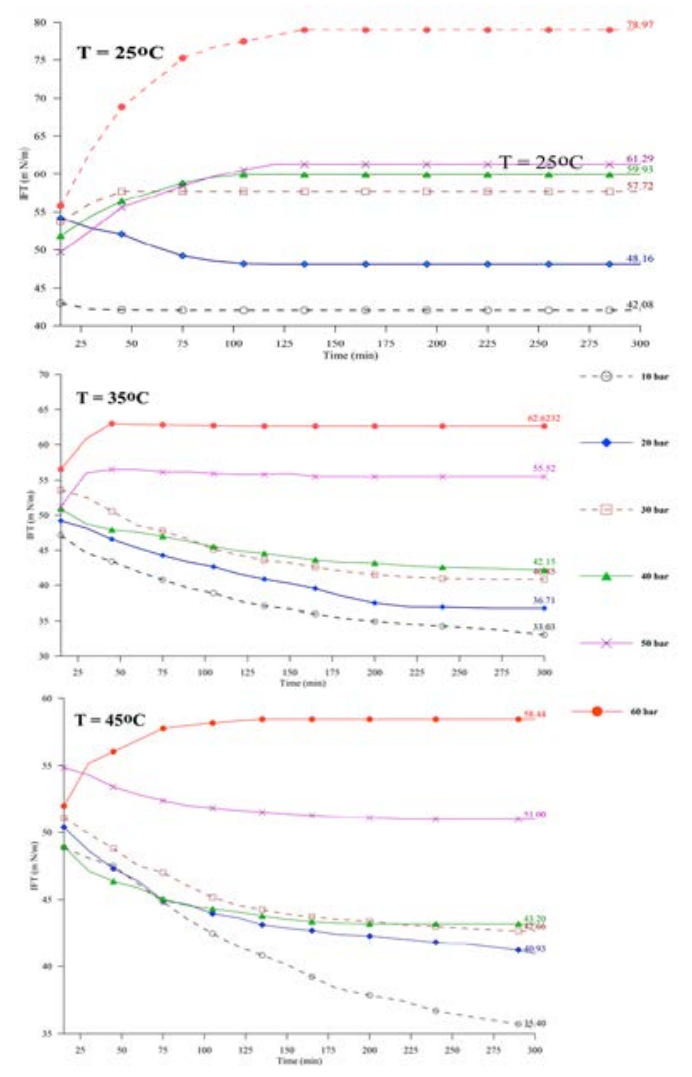

Fig. 2. Dynamic IFT between CW-n-decane system at 25oC, 35oC, and 45oC for a pressure range of $10-60 \mathrm{bar}$. 
Apart from the influence of $\mathrm{CO}_{2}$ solubility and density changes on IFT, increasing the temperature would cause additional physics that would affect the IFT. The kinetic energy and the entropy (mobility of the molecules) of the binary mixture $\left(\mathrm{CO}_{2}+\mathrm{n}\right.$-decane) are increased as the temperature is raised, this increases the total energy of the interface of the CW and binary mixture [10]. The increment in the total energy would reduce the free energy, which evidently results in the reduction of the IFT [10]. Hence, two phenomena having an opposing influence on IFT are present. First, IFT increment due to increment in density difference caused by an increase in $\mathrm{CO}_{2}$ solubility. Second, is the decrease in IFT (with time) due to increase in kinetic energy and the entropy due to increment in temperature. The behaviour of the IFT with time depends on which of these phenomena is dominant. Increasing the temperature, reduces the solubility of $\mathrm{CO}_{2}$ in n-decane and CW, however, the kinetic energy increases causing breakage of intermolecular bonds and reduces the free energy consequently reduces the IFT. This only explains the reduced IFT with temperature and not the presence of different threshold pressure at different temperatures. The threshold pressure (IFT trend transition), was demonstrated to increase with temperature. This may be explained by the need for high pressure to reduce the change in the entropy, hence increases the free energy consequently the IFT trend increases with pressure. Apart from an increase in kinetic energy and entropy of the molecules in the binary mixture, the $\mathrm{CO}_{2}$ solubility in $\mathrm{n}$-decane decreases. The decrease in $\mathrm{CO}_{2}$ solubility leads to a reduction in the mass transfer of $\mathrm{CO}_{2}$ into the binary mixture, eventually causing a lower reduction in density of the binary mixture, which may be observed from the data presented in Table I. Therefore, as the temperature is raised the influence of kinetic energy and entropy on IFT is dominant compared to the influence of $\mathrm{CO}_{2}$ solubility. This explains the observed upward shift in the "threshold pressures" with the increase in temperature. However, at high pressures (50 and 60 bar at $35^{\circ} \mathrm{C}$ and 60 bar at $45^{\circ} \mathrm{C}$ ), the $\mathrm{CO}_{2}$ solubility dominates kinetics, causing an increase in IFT with time at these pressures.

TABLE I: The Percentage Change In Density of the N-Decane AND $\mathrm{CO}_{2}$ MOLE FRACTION IN N-DECANE AT $25^{\circ} \mathrm{C}, 35^{\circ} \mathrm{C}$, AND $45^{\circ} \mathrm{C}$ FOR 10 BAR, 40 BAR, AND 60 BAR

\begin{tabular}{cccc}
\hline Temperature & $25^{\circ} \mathrm{C}$ & $35^{\circ} \mathrm{C}$ & $45^{\circ} \mathrm{C}$ \\
\hline Pressure & & $10 \mathrm{bar}$ \\
\hline \% density change & -2.258 & -1.52 & -1.73 \\
$\mathrm{CO}_{2}$ Mole fraction & 0.0019 & 0.0012 & 0.0014 \\
Pressure & \multicolumn{3}{c}{$40 \mathrm{bar}$} \\
\% density change & -28.48 & -16.02 & -9.865 \\
$\mathrm{CO}_{2}$ Mole fraction & 0.167 & 0.079 & 0.044 \\
Pressure & \multicolumn{3}{c}{$60 \mathrm{bar}$} \\
\% density change & -45.43 & -35.43 & -18.60 \\
$\mathrm{CO}_{2}$ Mole fraction & 0.602 & 0.346 & 0.121 \\
\hline \hline
\end{tabular}

Fig. 3 shows the images of the PD (n-decane $+\mathrm{CO}_{2}$ ) at the equilibrium condition at three pressure $(10,40$, and $60 \mathrm{bar})$ and three temperatures $\left(25^{\circ} \mathrm{C}, 35^{\circ} \mathrm{C}\right.$, and $\left.45^{\circ} \mathrm{C}\right)$. The objective of presenting these images is to validate through visual observations the relation between different physics presented in Fig. 2. In the pendant drop method, the interfacial tension is estimated from the shadow of the image of a pendant drop using drop shape analysis. Uniform density region would indicate negligible density difference (gradient) (like the surrounding $\mathrm{CW}$ ), and such regions have a lighter shadow, while the regions with considerable density difference will have a darker shadow. The images in the first row (Fig. 3) represent the equilibrium n-decane drop at $10 \mathrm{bar}$ and $25^{\circ} \mathrm{C}$, $35^{\circ} \mathrm{C}$, and $45^{\circ} \mathrm{C}$. It may be observed that for all experimental temperatures, the $\mathrm{PD}$ has a thick dark region near the interface and then the darkness fades towards the center of the drop, indicating a non-uniform distribution of $\mathrm{CO}_{2}$ mass within the drop. From, the discussion in Fig. 2 this would lead to a reduction in IFT (due to the lower influence of $\mathrm{CO}_{2}$ solubility), the same has been observed in Fig. 2. Further, the density distribution is similar to $10 \mathrm{bar}$ at all three experimental temperatures, indicating that IFT variations would be similar, which validates with the observed reduction in IFT at $10 \mathrm{bar}$ for all three temperatures (Fig. 2A, 2B, and 2C). From the second row ( 40 bar at $25^{\circ} \mathrm{C}, 35^{\circ} \mathrm{C}$, and $45^{\circ} \mathrm{C}$ ), there is a difference among temperature, n-decane drop at $25^{\circ} \mathrm{C}$ seems to be lighter and uniform distribution of $\mathrm{CO}_{2}$ than $35^{\circ} \mathrm{C}$ and $45^{\circ} \mathrm{C}$, a considerable non-uniformity in shadow $\left(\mathrm{CO}_{2}\right.$ distribution $)$ at $35^{\circ} \mathrm{C}$ and $45^{\circ} \mathrm{C}$. Going, by this, the IFT variations at $25^{\circ} \mathrm{C}$ should be different compared to $35^{\circ} \mathrm{C}$ and $45^{\circ} \mathrm{C}$. In Fig. 2, it was observed that at $25^{\circ} \mathrm{C}$ for 40 bar the IFT increased with time up to equilibrium, whereas $35^{\circ} \mathrm{C}$ and $45^{\circ} \mathrm{C}$ showed a decrease in IFT. From the third row $\left(40\right.$ bar at $25^{\circ} \mathrm{C}, 35^{\circ} \mathrm{C}$, and $45^{\circ} \mathrm{C}$ ), the shadows of the n-decane drop are similar at all the three temperature, indicating a similar variation of IFT with time. In Fig. 2, it was observed that for three temperatures at 60 bar the IFT increased with time up to equilibrium.

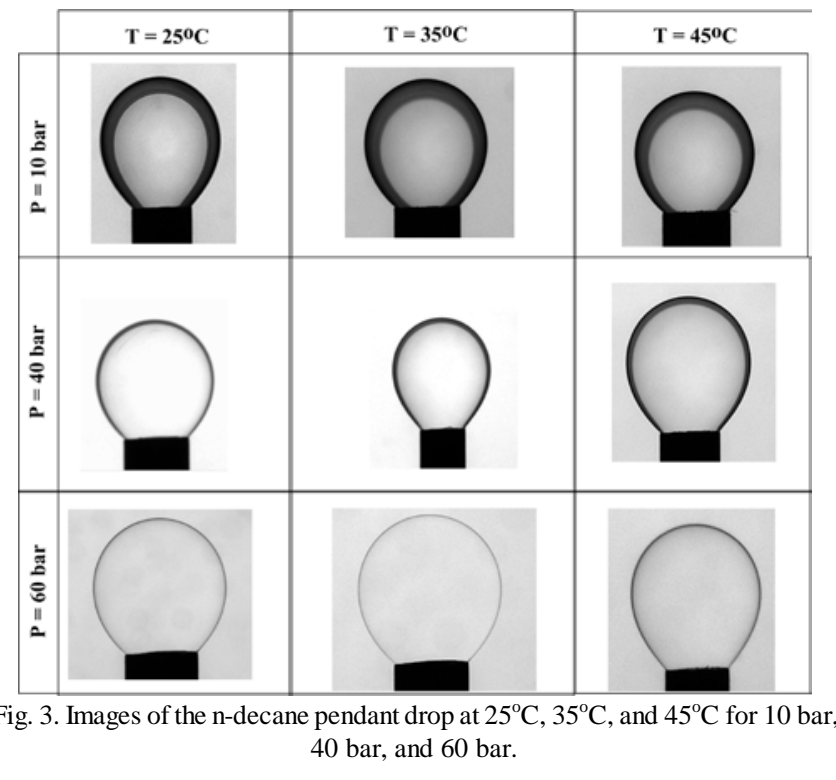

Fig. 4 show the influence of temperature on the equilibrium IFT at three temperatures $\left(25^{\circ} \mathrm{C}, 35^{\circ} \mathrm{C}\right.$, and $\left.45^{\circ} \mathrm{C}\right)$ and various pressures (10-70 bar). This section discusses the variation of IFT with pressure at $25^{\circ} \mathrm{C}$ and $45^{\circ} \mathrm{C}$. The variation of IFT with 
pressure between $35^{\circ} \mathrm{C}$ and $45^{\circ} \mathrm{C}$ is complicated and will be dealt with in detail in the following paragraph and this paragraph the focus will be mainly on $25^{\circ} \mathrm{C}$ and $45^{\circ} \mathrm{C}$. It may be observed from Fig. 4 that regardless of the experimental temperature, equilibrium IFT of CW-PD increases with the pressure, which is unlike the results from the literature for the $\mathrm{CO}_{2}$-hydrocarbon system [9], [11]. Few important observations may be made in Fig. 4, first, the relation of interfacial tension with pressure for the present system is unlike $\mathrm{CO}_{2}$-hydrocarbon system [9], where the IFT decrease with increase in pressure. Second, the relation of interfacial tension with pressure observed in Fig. 4 is similar to the water-n-decane systems. In water-n-decane systems, the IFT linearly increased with pressure. Wiegand and Franck [12] reported the IFT of the water- $n$-decane system to change between 50 to $55 \mathrm{~m} \mathrm{~N} / \mathrm{m}$ for a pressure range 0 to 2500 bar at $25^{\circ} \mathrm{C}$. However, in the present study the water is carbonated (CW) and the presence of $\mathrm{CO}_{2}$ in the water has led to an increase in the IFT $\left(25^{\circ} \mathrm{C}\right)$ when compared to previously reported IFT values for the water-n-decane system, although the trend of IFT with pressure is similar. Hence the carbonation of water increases the IFT of the water-hydrocarbon system. The changes in the density of water and hydrocarbon due to dissolution and diffusion of $\mathrm{CO}_{2}$ respectively may be credited for the observed increment in equilibrium IFT with pressure. Third, for $25^{\circ} \mathrm{C}$ and $45^{\circ} \mathrm{C}$, at isobaric conditions, the IFT decreases as temperature is increased. Raising the temperature reduces the $\mathrm{CO}_{2}$ solubility in hydrocarbons and water, leading to an increase in IFT [5]. Further, raising the temperature increases the total entropy and reduces the Gibbs free energy, resulting in an observed reduction in IFT [10] as the temperature is raised from $25^{\circ} \mathrm{C}$ to $45^{\circ} \mathrm{C}$. Additionally, Fig. 5 depicts the density difference between $\mathrm{CW}$ and $\mathrm{PD}$ at equilibrium (same conditions as that of equilibrium IFT) at $25^{\circ} \mathrm{C}, 35^{\circ} \mathrm{C}$, and $45^{\circ} \mathrm{C}$ and $10-70$ bar. It may be observed from Fig. 5 that the density difference increases with increase in pressure at all temperatures. The IFT is directly proportional to the density difference between the two immiscible fluids [10], [11], hence, the greater the density difference, the larger the IFT.

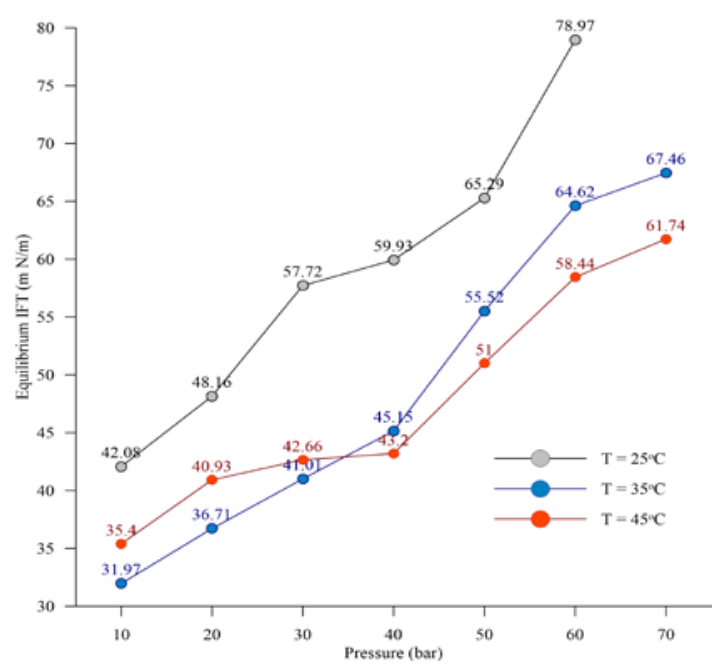

Fig. 4. Equilibrium IFT at $25^{\circ} \mathrm{C}, 35^{\circ} \mathrm{C}$, and $45^{\circ} \mathrm{C}$ for n-decane hydrocarbon drop and at a pressure range of $10-70$ bar.
In addition to $25^{\circ} \mathrm{C}$ and $45^{\circ} \mathrm{C}$ Fig. 4 shows the equilibrium IFT (m N/m) for CW-n-decane system at $35^{\circ} \mathrm{C}$ and at a pressure range of 10-70 bar. The variation of equilibrium IFT between $35^{\circ} \mathrm{C}$ and $45^{\circ} \mathrm{C}$ is not as straightforward as between $25^{\circ} \mathrm{C}$ and $45^{\circ} \mathrm{C}$. It may be observed from Fig. 4 that up to 30 bar the IFT at $35^{\circ} \mathrm{C}$ is lower than that of $45^{\circ} \mathrm{C}$, this is contradicting the theory presented in the above discussion, although IFT at $25^{\circ} \mathrm{C}$ is the maximum. Above 30 bar (40-70 bar) the IFT vs temperature returns to normal trend (IFT inversely proportional to temperature), with IFT being maximum for $25^{\circ} \mathrm{C}$, minimum for $45^{\circ} \mathrm{C}$ and intermediate for $35^{\circ} \mathrm{C}$ at isobaric conditions. The proximity of $35^{\circ} \mathrm{C}$ to the critical temperature of $\mathrm{CO}_{2}\left(31.1^{\circ} \mathrm{C}\right)$, may be credited for the observed behaviour of IFT with pressure. A similar change in slope of equilibrium IFT with temperature has been observed by Zolghadr, et al. [13] ( $\mathrm{CO}_{2}$-hydrocarbon system), Bagalkot and Hamouda [9] ( $\mathrm{CO}_{2}$-hydrocarbon system), and Karnanda, et al. [14] (surfactant flooding). In literature, the increase in IFT with increment in temperature has been credited to decrease in the solubility [5], while the decrease in IFT with the increment in temperature has been credited to increase in the total entropy and hence, reduction in Gibbs free energy [10]. Both of them may be true of the CW-hydrocarbon system, at low pressures (below 40 bar) the decrease in $\mathrm{CO}_{2}$ solubility plays a major role, thus increasing the IFT. However, at medium and high pressures (above $40 \mathrm{bar}$ ) it seems that the reduction in Gibbs free energy due to increase in temperature dominates the effect of reduction in $\mathrm{CO}_{2}$ solubility, giving rise to a decrease in IFT with an increase in temperature $\left(35^{\circ} \mathrm{C}\right.$ to $45^{\circ} \mathrm{C}$ ). Apart from these two factors, the density difference between the $\mathrm{CW}$ and the hydrocarbon drop plays an important part. It may be observed from Fig. 5 the variation of density difference with temperature follows a similar trend to equilibrium IFT (Fig. 4) between $35^{\circ} \mathrm{C}$ and $45^{\circ} \mathrm{C}$. Thus, confirming the density difference along with the $\mathrm{CO}_{2}$ solubility and entropy change (reduction in Gibbs free energy) influence the IFT of CW-hydrocarbon system, especially above the critical temperature.

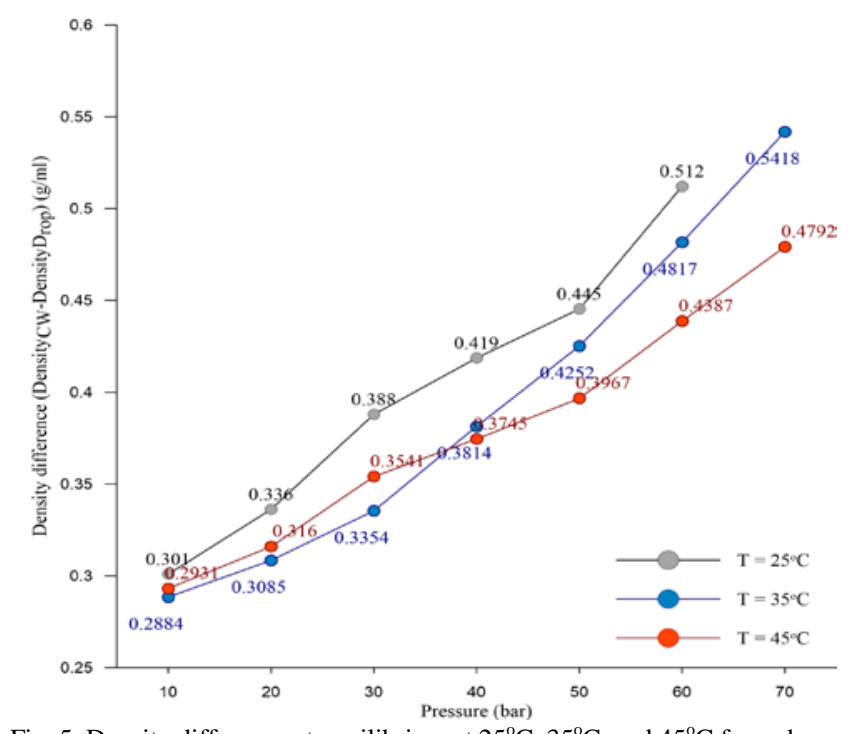

Fig. 5. Density difference at equilibrium at $25^{\circ} \mathrm{C}, 35^{\circ} \mathrm{C}$, and $45^{\circ} \mathrm{C}$ for n-decane hydrocarbon drop and at a pressure range of 10-70 bar. 


\section{CONCLUSIONS}

The present study through experiments and mathematical model study the influence of temperature on the interfacial tension (IFT) for a system consisting of carbonated water (CW) and hydrocarbon at non-isothermal and non-isobaric conditions. Hence, address and understand the inconsistencies in results reported in the literature between temperature and IFT.

The time-dependent IFT analysis showed the presence of a threshold pressure for a given temperature above which the IFT increases with time and below which the IFT decreases. The increase or decrease of IFT with time for different pressure was credited to a complex relationship between the density alterations due to increased $\mathrm{CO}_{2}$ mass transfer, $\mathrm{CO}_{2}$ solubility, and kinetic energy and entropy changes controlled by temperature. Depending which of these physics is dominating the IFT increases or decreases with time during the diffusion of $\mathrm{CO}_{2}$.

For the CW-n-decane system, the equilibrium IFT increases as pressure increases (10-70 bar). The equilibrium the value of the IFT depend on density difference influenced by $\mathrm{CO}_{2}$ mass transfer, and $\mathrm{CO}_{2}$ solubility at a given temperature. Further, it was observed that the equilibrium IFT at $25^{\circ} \mathrm{C}$ was higher than at $35^{\circ} \mathrm{C}$ and $45^{\circ} \mathrm{C}$. Increase in kinetic energy and entropy due to increment in temperature was credited to this.

The variation of equilibrium IFT between $35^{\circ} \mathrm{C}$ and $45^{\circ} \mathrm{C}$ is not as straightforward as between $25^{\circ} \mathrm{C}$ and $45^{\circ} \mathrm{C}$ or $25^{\circ} \mathrm{C}$ and $35^{\circ} \mathrm{C}$. Up to a certain pressure the equilibrium IFT at $35^{\circ} \mathrm{C}$ is lower than at $45^{\circ} \mathrm{C}$, and beyond this pressure, the equilibrium IFT at $35^{\circ} \mathrm{C}$ is greater than at $45^{\circ} \mathrm{C}$. The reduction in Gibbs free energy which reduces the IFT and increases in IFT due to a decrease in solubility as temperature increases, the balance between these physics determine the observed behaviour. Further, it was found that the density difference across the interface showed a similar variation with pressure as equilibrium IFT at $35^{\circ} \mathrm{C}$ and $45^{\circ} \mathrm{C}$, indicating the dependency of the IFT on the density difference.

\section{REFERENCES}

[1] M. Riazi, M. Sohrabi, and M. Jamiolahmady, "Experimental study of pore-scale mechanisms of carbonated water injection," Transport in Porous Media, vol. 86, no. 1, pp. 73-86, 2011.

[2] M. Sohrabi, M. Riazi, M. Jamiolahmady, N. I. Kechut, S. Ireland, and G. Robertson, "Carbonated water injection (CWI)-a productive way of using $\mathrm{CO}_{2}$ for oil recovery and $\mathrm{CO}_{2}$ storage,” Energy Procedia, vol. 4, pp. 2192-2199, 2011.

[3] N. I. Kechut, M. Sohrabi, and M. Jamiolahmady, "Experimental and numerical evaluation of carbonated water injection (CWI) for improved oil recovery and $\mathrm{CO}_{2}$ storage,” in Proc. SPE Europec/Eage Annual Conference and Exhibition, Society of Petroleum Engineers, 2011.

[4] D. Mackay and K. Hossain, "Interfacial tensions of oil, water, chemical dispersant systems,” The Canadian Journal of Chemical Engineering, vol. 60, no. 4, pp. 546-550, 1982.
[5] D. Yang, P. Tontiwachwuthikul, and Y. Gu, "Interfacial tensions of the crude oil+ reservoir brine $+\mathrm{CO}_{2}$ systems at pressures up to $31 \mathrm{MPa}$ and temperatures of $27 \mathrm{C}$ and 58 C," Journal of Chemical \& Engineering Data, vol. 50, no. 4, pp. 1242-1249, 2005.

[6] P. Linstrom and W. Mallard, "NIST chemistry webbook, NIST standard reference database number 69, National Institute of Standards and Technology, Gaithersburg MD, 20899,” 2010.

[7] Y. B. Chang, B. K. Coats, and J. S. Nolen, “A compositional model for CO 2 floods including $\mathrm{CO}_{2}$ solubility in water," in Proc. Permian Basin Oil and Gas Recovery Conference, 1996, Society of Petroleum Engineers.

[8] Z. Duan and R. Sun, “An improved model calculating $\mathrm{CO}_{2}$ solubility in pure water and aqueous $\mathrm{NaCl}$ solutions from 273 to $533 \mathrm{~K}$ and from 0 to 2000 bar,” Chemical Geology, vol. 193, no. 3, pp. 257-271, 2003.

[9] N. Bagalkot and A. A. Hamouda, "Experimental and numerical method for estimating diffusion coefficient of the carbon dioxide into light components,” Industrial \& Engineering Chemistry Research, vol. 56, no. 9, pp. 2359-2374, 2017.

[10] B. Honarvar, et al., "Experimental investigation of interfacial tension measurement and oil recovery by carbonated water injection: A Case study using core samples from an iranian carbonate oil reservoir," Energy \& Fuels, vol. 31, no. 3, pp. 2740-2748, 2017.

[11] M. Ghorbani and A. H. Mohammadi, "Effects of temperature, pressure and fluid composition on hydrocarbon gas-oil interfacial tension (IFT): An experimental study using ADSA image analysis of pendant drop test method,” Journal of Molecular Liquids, vol. 227, pp. 318-323, 2017.

[12] G. Wiegand and E. Franck, "Interfacial tension between water and non-polar fluids up to $473 \mathrm{~K}$ and 2800 bar," Berichte der Bunsengesellschaft für physikalische Chemie, vol. 98, no. 6, pp. 809-817, 1994.

[13] A. Zolghadr, M. Escrochi, and S. Ayatollahi, "Temperature and composition effect on $\mathrm{CO}_{2}$ miscibility by interfacial tension measurement," Journal of Chemical \& Engineering Data, vol. 58, no. 5, pp. 1168-1175, 2013.

[14] W. Karnanda, M. Benzagouta, A. AlQuraishi, and M. Amro, "Effect of temperature, pressure, salinity, and surfactant concentration on IFT for surfactant flooding optimization," Arabian Journal of Geosciences, vol. 6, no. 9, pp. 3535-3544, 2013.

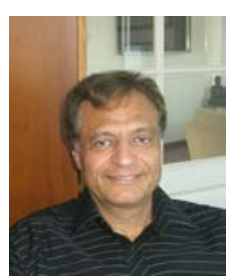

Aly A. Hamouda is a professor at Department of Petroleum Technology, University of Stavanger, Norway. He completed his Ph.D from, DIC, Imperial College, London University. He has over 15 years of industrial experience at Phillips Petroleum (currently ConocoPhillips) and simultaneously Adjunct professor. His research interests include wide topics like EOR (LSW, $\mathrm{CO}_{2}$, LSW, polymer, carbonated water), $\mathrm{CO}_{2}$ sequestration, in-depth reservoir treatment by polymer gel, oil drag reduction in pipelines, flow assurance and nanotechnology and wettability alteration.

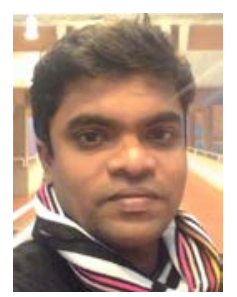

Nikhil Bagalkot is a Ph.D scholar at Department of Petroleum Engineering, University of Stavanger, Norway. He completed his master by research from Department of Ocean Engineering, Indian Institute of Technology Madras, India, in 2015. He works on a wide range of interdisciplinary topic which includes enhanced oil recovery, geothermal, contamination transport, and reservoir modelling trough experimental and modelling approach. Currently, he is working on assessing the carbonated water as an effective couple recovery and sequestration method, through lab scale flooding and mass transfer experiments. 